\title{
A national stakeholder consensus study of (rossmatk challenges and priorities for clinical learning environments in postgraduate medical education
}

Caroline Kilty ${ }^{1}$, Anel Wiese ${ }^{1}$, Colm Bergin², Patrick Flood ${ }^{3}, \mathrm{Na} \mathrm{Fu}^{4}$, Mary Horgan $^{5}$, Agnes Higgins ${ }^{6}$, Bridget Maher ${ }^{1}$, Grainne O'Kane ${ }^{7}$, Lucia Prihodova ${ }^{7}$, Dubhfeasa Slattery ${ }^{8}$, Slavi Stoyanov ${ }^{9}$ and Deirdre Bennett ${ }^{*}$ (D)

\begin{abstract}
Background: High quality clinical learning environments (CLE) are critical to postgraduate medical education (PGME). The understaffed and overcrowded environments in which many residents work present a significant challenge to learning. The purpose of this study was to develop a national expert group consensus amongst stakeholders in PGME to; (i) identify important barriers and facilitators of learning in CLEs and (ii) indicate priority areas for improvement. Our objective was to provide information to focus efforts to provide high quality CLEs.

Methods: Group Concept Mapping (GCM) is an integrated mixed methods approach to generating expert group consensus. A multi-disciplinary group of experts were invited to participate in the GCM process via an online platform. Multi-dimensional scaling and hierarchical cluster analysis were used to analyse participant inputs in regard to barriers, facilitators and priorities.

Results: Participants identified facilitators and barriers in ten domains within clinical learning environments. Domains rated most important were those which related to residents' connection to and engagement with more senior doctors. Organisation and conditions of work and Time to learn with senior doctors during patient care were rated as the most difficult areas in which to make improvements.

Conclusions: High quality PGME requires that residents engage and connect with senior doctors during patient care, and that they are valued and supported both as learners and service providers. Academic medicine and health service managers must work together to protect these elements of CLEs, which not only shape learning, but impact quality of care and patient safety.
\end{abstract}

Keywords: Graduate medical education, Postgraduate medical education, Clinical learning environment, European working time directive, Duty hours regulations, Group concept mapping

\section{Background}

The Clinical Learning Environment (CLE) has been described as 'the foundation of graduate medical education' [1] and refers to the social, cultural and material context in which residents learn while they work [2]. Social theories of learning emphasise the importance of environment for workplace learning [3-7]. Supportive clinical

\footnotetext{
* Correspondence: d.bennett@ucc.ie

${ }^{1}$ Medical Education Unit, School of Medicine, University College Cork, Cork, Ireland

Full list of author information is available at the end of the article
}

learning environments should afford residents access to supervised participation in patient care, coaching, assessment and feedback, deliberate practice, teamwork, peer collaboration and observable models of practice $[8,9]$. Learners' engagement with the affordances of the CLE leads to acquisition of practical knowledge, skills and attitudes as well as to the development of professional identity [10-17]. Supportive clinical learning environments for postgraduate medical education (PGME) contribute to better patient care through these directs effects on residents and their current and future practice 
$[18,19]$. Regulatory bodies internationally have promoted and mandated the quality assurance of clinical learning environments, signalling their importance [20-23]. High quality clinical learning environments matter because they impact both workplace learning and the quality and safety of clinical care.

Many residents work, learn and develop their professional identities in underfunded [24-26], understaffed [27], uncontrolled and overcrowded clinical environments [28-30]. This presents a significant challenge for learning and for patient safety. The UK General Medical Council (GMC), has stated that 'Patient safety is inseparable from a good learning environment and culture that values and supports learners and educators' [31]. The GMC annual training survey report 2016 [32] acknowledged the difficulties created by increased demand and short-staffing. One in three supervisors reported that they did not have enough time to fulfil their role. Selfreported heavy workloads in that survey were associated with a greater likelihood of residents feeling forced to work beyond their competence and having patient safety concerns [32]. Intern and resident learning has been reported to decline once a critical level of workload is exceeded [33]. These conditions are associated with doctor burnout [34, 35], lower levels of staff engagement, health and wellbeing [27, 36, 37], all of which negatively impact learning, as well as lower levels of patient satisfaction, poorer standards of patient care [38] and higher mortality [27]. In addition to the issue of excessive workload, the effects of duty hours restrictions, in place in North America and Europe, on learning, patient safety and workload remain uncertain [39-42]. Both the Accreditation Council for Graduate Medical Education (ACGME) [43] and GMC [31] have explicitly linked CLE with quality of patient care and there have been calls for the greater alignment of educational and patient outcomes [44].

Provision of high quality clinical learning environments is critical to the overlapping missions of postgraduate medical education and the wider medical profession. In the UK and the Republic of Ireland, where national health services are under strain, low morale and deep dissatisfaction amongst residents about their working conditions has led to strike action $[45,46]$. An exodus of medical graduates and difficulty in recruitment to residencies in both countries $[47,48]$ send a stark message that change is needed and raise the question; what can academic medicine do to enhance clinical learning environments?

Strategic planning to protect and enhance clinical learning environments is essential in order to mitigate the negative effects of the wider social, economic and political climate. Prioritisation of the most important facilitators and identification of 'easy wins' are important steps in this process. The purpose of this study was to develop a national expert group consensus amongst a range of relevant stakeholders; senior doctors, residents, patients, allied healthcare professionals and healthcare managers allowing us to; (i) identify important barriers and facilitators of learning in clinical environments and (ii) indicate priority areas for improvement. Our overarching objective was to provide information to guide policy makers and those tasked with the delivery of graduate medical education in tackling the provision of high quality clinical learning environments in challenging times.

\section{Methods}

Ethical approval for this study was granted by the Clinical Research Ethics Committee of the Cork University Hospitals, Ireland.

\section{Conceptual orientation}

This is an integrated mixed methods study which has been conducted from a pragmatic epistemological stance. This position emphasises the utility of both quantitative and qualitative research approaches to answer a research question, over any epistemological or ontological discordance between them. Within this perspective the interpretative elements of our study have been conducted from a sociocultural stance, which holds that learning takes place during social interaction in cultural and historical settings [49].

\section{Setting}

This national study was conducted in the Republic of Ireland, which has a comprehensive, government funded public healthcare system. On completion of a medical degree programme graduates spend a year as an intern before becoming fully registered medical practitioners. Those entering hospital specialties then spend $6-8$ years in training programmes which are similar to UK Foundation, Core and Specialist training and broadly analogous to North American residencies and fellowships. A variety of terms are used, both internationally and nationally, to describe doctors in postgraduate medical education, these include; junior doctors, trainees, doctors-in-training, non-consultant hospital doctors and residents. Similarly, terms to describe senior doctors include consultants, attending physicians, supervisors and trainers. The latter two terms suggesting a formal educational role. In this paper we will use the terms resident and senior doctor unless directly quoting participants.

This study is part of a larger project funded by the Health Research Board, Ireland. The research team is a multi-disciplinary group including residents, senior doctors, medical educators, experts in organisational behaviour, and representatives of nursing and allied healthcare professions as well as patient representation. 


\section{Recruitment and participation}

We issued an invitation via email to experts and stakeholders in postgraduate medical education nationally to participate in a consensus building process. We purposively selected attending physicians, residents, health service managers, allied healthcare professionals and patient representatives, on the basis of their expertise and experience of clinical learning environments. Doctors with senior roles in postgraduate medical education were targeted, as were clinicians who supervise trainees daily in the workplace. A range of allied healthcare professionals were targeted in a similar manner. Each of the stakeholder groups included interfaces with postgraduate training 'on the ground' in the clinical environment and/or contributes to the policy and structures which govern training. We hypothesised that they might provide unique perspectives in respect of our research questions.

\section{Data collection}

Group Concept Mapping (GCM) is a novel integrated mixed method approach to identify an expert group's understanding about a topic. GCM builds on the strengths of other structured consensus building methods, such the Delphi method, mitigating some of their weaknesses [50]. The aim of GCM is to depict unique ideas on a particular topic by converting complex qualitative data into conceptual maps [51] showing how individual ideas are related to each other, and generating rating data relating to the relative importance of an idea, and its perceived achievability [51].

GCM consists of five phases:

Phase 1: Brainstorming \& Pruning: We provided participants with a web-based link to an online platform for data collection [52]. Participants completed a short demographic questionnaire and identified facilitators and/or barriers to learning in clinical environments in response to the following prompt:

\section{One specific barrier or facilitator to trainee doctors learning within the clinical environment is...'}

Participants could provide as many statements as they wished and we asked for a minimum of five from each. The second step was idea pruning, a data cleaning process undertaken by the research team. We reviewed the initial list of statements for any repetition, ambiguity or more than one idea. We deleted, re-worded or split statements as required.

Phases 2 \& 3: Sorting \& Rating: In keeping with the GCM method, a subgroup of the original participants was selected to sort the edited list of statements into groups, based on similarity of the ideas therein. These participants were then asked to rate each statement for importance using the following prompt;

'Rate the relative importance of each statement as a facilitator or a barrier to trainee doctors' learning within the clinical environment using a scale ranging from 1 (relatively unimportant) to 5 (extremely important).'

The process was then repeated for each statement regarding 'ease to address'.

Phase 4: Data Analysis: Concept System Global software was used for the quantitative data analysis. Multidimensional scaling produced a point map of the statements based on the principle that statements which participants had more frequently grouped together during the sorting process on the basis of their similarity, appear close to each other on the point map [53]. A bridging value was calculated for each statement. This is a statistic ranging from 0 to 1 which indicates how often a statement is grouped with others adjacent to it on the concept map, and whether participants have grouped it with others further away.

Hierarchical cluster analysis embedded in GCM initially treats each individual idea as a separate cluster, and continues to merge ideas until it arrives at one cluster [54]. Mean bridging value for a cluster is calculated on the individual bridging values of statements composing that cluster [55]. A lower bridging value indicates that a statement has greater cohesion with others in that cluster. Lower mean bridging value for a cluster corresponds to a greater level of agreement on the content of that cluster [55].

Mean rating scores for importance and ease to address for each statement and cluster were calculated. The clusters and ratings produced by doctors were compared with those produced by the other participants.

Phase 5: Interpretation of the results: The GCM software generated an initial cluster solution and offered a sequence of cluster merges which could be undertaken if there was sufficient conceptual similarity between clusters to do so. This qualitative element of the mixed methods analysis is underpinned by researcher interpretation and judgement [53]. DB, AW and $\mathrm{CK}$ co-constructed a thematic interpretation of the statements in each cluster during a series of meetings. Judgements to merge clusters or not were based on similarity of meaning of the statements therein. Once merges were agreed, DB, AW and CK proposed meaningful labels for the final clusters, informed by our orientation towards social theories of learning e.g. Communities of Practice. These were labels were debated and finalised with the wider multiprofessional research team. 


\section{Results}

Fifty-five participants contributed to the first phase of the GCM, brainstorming. All stakeholder groups were represented. Sixty-five percent of participants were female. Table 1 shows their distribution by category.

Two hundred and six statements relating to facilitators and barriers to learning in clinical environments were generated. Following pruning, 97 unique ideas remained; 78 were barriers to learning and 19 were facilitators. Twenty-seven participants contributed to the sorting and rating phase.

Following review as outlined above, a 10 cluster solution describing key domains of clinical learning environments, shown in Fig. 1, was determined. This decision was based on the conceptual sense of merging clusters based on the themes of the statements within them.

Clusters were named as shown in Table 2 and Fig. 1. Mean cluster bridging values (BV), which are an indicator of the coherence of the cluster, are shown in Table 2. The lower the bridging value the more cohesive the cluster. Sample statements from each cluster are also presented.

Figure 1 shows the relationship of the clusters to each other; proximity representing domains which are more closely related to each other and distance vice versa. The role of patients in doctors' learning can be seen to be relatively distant from the remaining 9 clusters indicating that it is conceptually more distinct. Work place culture is at the centre of the map and is immediately adjacent to 7 of the 9 remaining clusters which suggests that most key aspects of clinical learning environments are linked to culture. Time to learn with senior doctors during patient care is relatively distant from Content, assessment and continuity of training and Trainer (Senior doctor) skill and support and these appear to represent two distinct aspects of clinical learning environments; the informal learning that happens while delivering patient care, and way in which that learning is structured, organised and resourced as part of a residency programme.

\section{Rating}

All clusters were rated as important to address, with mean ratings ranging from 3.42 to 3.96 on a scale from

Table 1 Participants by category

\begin{tabular}{lll}
\hline Participant Category & $\mathrm{n}$ & $\%$ \\
\hline Resident & 10 & $18 \%$ \\
Senior doctor / supervisor & 9 & $16 \%$ \\
Senior Strategic Role in PGMET & 10 & $18 \%$ \\
Patient Representative & 4 & $7 \%$ \\
Allied Healthcare Professional & 13 & $24 \%$ \\
Health Services Management & 9 & $16 \%$ \\
Total & 55 & $100 \%$ \\
\hline
\end{tabular}

1 to 5 . There was a wider spread of mean ratings of clusters on ease to address (2.37-3.68). We compared the ratings provided by doctors $(n=19)$ and non-doctors $(n=$ 8 ) and found that these were highly correlated, $r=0.7$ for importance and $r=0.99$ for ease to address. The nondoctor group rated Time to learn with senior doctors during patient care and Organisation and conditions of work as relatively less important, third and sixth out of ten respectively, compared with doctors, who rated these the top two most important domains. Both groups rated The role of patients in doctors' training, Content, assessment and continuity of training, and Trainer (senior doctor) skill and support as least important, in that order Table 3.

\section{Individual statements}

Ratings for individual statements identified some very specific areas which participants viewed both important and relatively easy to address. Feedback was most prominent amongst these;

Gaining good regular feedback on their performance by those in the immediate clinical environment is a facilitator to learning (Importance 4.56, Ease to address 4.33).

Patient feedback to the young doctor is beneficial and should be encouraged, especially in how they have interacted with the patient (Importance 4.12, Ease to address 4.04).

Protected time for teaching and learning was a second prominent theme;

Protected time being allocated to both senior doctors and residents to facilitate tutorials (Importance 4.0, Ease to address 3.42).

Bleep free educational sessions are still aspirational in most hospitals (Importance 3.8, Ease to address 3.54).

\section{Discussion}

At the outset of this study we aimed to provide information to guide policy makers and those tasked with the delivery of postgraduate medical education in tackling the provision of high quality clinical learning environments in challenging times. We have done so by reporting stakeholders' consensus on the most important domains in CLEs, and the most important barriers/facilitators to learning within them. We have also reported stakeholders' perceptions of the relative ease with which these issues can be addressed. These findings can 


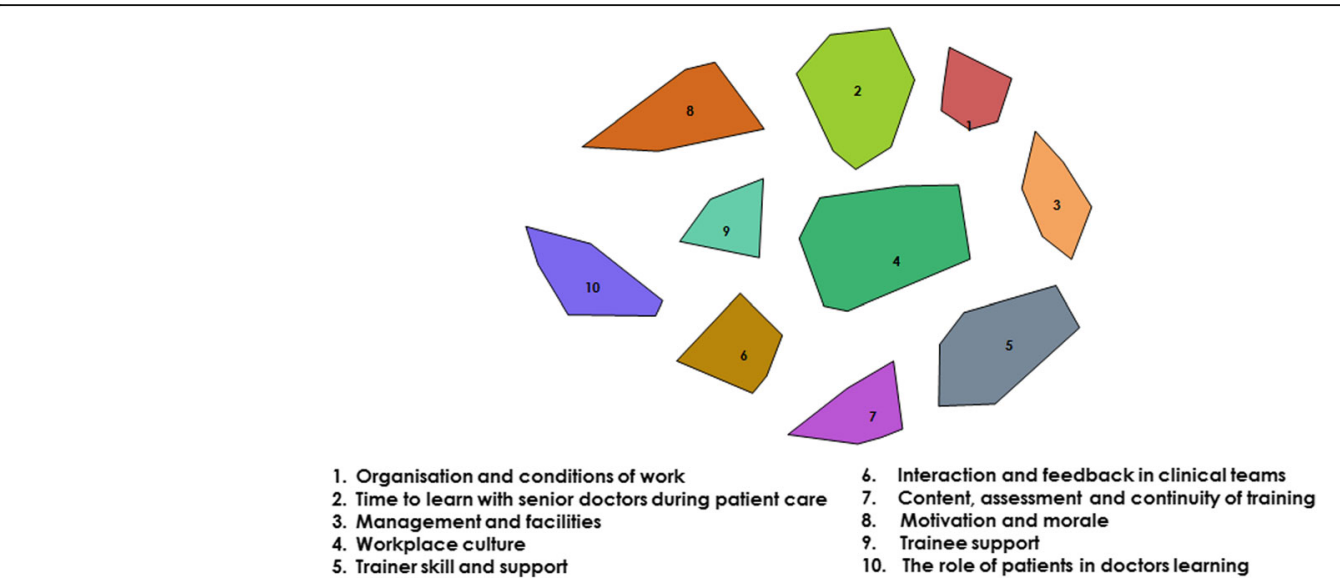

Fig. 110 cluster solution with domain names

contribute to targeted improvements to clinical learning environments.

\section{Principal findings}

In this study stakeholders identified ten distinct domains within clinical learning environments. These domains were mapped to provide a visual representation of their relationships. Workplace culture lay in a central position on the cluster map (Fig. 1), directly adjacent to 7 of the other clusters, suggesting that most aspects of clinical learning environments are culturally embedded. There was consensus amongst doctors and other participants

Table 2 Ten clusters with names, definitions and sample statements for each

\begin{tabular}{|c|c|c|c|c|}
\hline & Title and Definition & $\begin{array}{l}\text { Mean } \\
\text { BV }\end{array}$ & Sample Statement & BV \\
\hline 1 & $\begin{array}{l}\text { Organisation and conditions of work - relating to the tension } \\
\text { between providing service in busy environments and needing } \\
\text { time to reflect and learn }\end{array}$ & 0.19 & $\begin{array}{l}\text { Barrier: Clinical areas are too busy and this acts as a barrier } \\
\text { to residents' learning. }\end{array}$ & 0.05 \\
\hline 2 & $\begin{array}{l}\text { Time to learn with senior doctors during patient care - relating } \\
\text { to the way that residents learn from work alongside senior doctors } \\
\text { as they follow the patient pathway }\end{array}$ & 0.23 & $\begin{array}{l}\text { Barrier: Time pressure at work has meant that the mentorship/ } \\
\text { apprenticeship role is lost and residents no longer have the } \\
\text { time/opportunity to discuss a case in-depth with a Senior Doctor. }\end{array}$ & 0.11 \\
\hline 3 & $\begin{array}{l}\text { Management and facilities - relating to the way in which hospital } \\
\text { management values and facilitates training and the provision of } \\
\text { facilities to support training at hospital sites }\end{array}$ & 0.46 & $\begin{array}{l}\text { Barrier: A lack of commitment by hospital management teams } \\
\text { to training. Management support for the training element of } \\
\text { the workplace is inadequate - seen as very secondary to } \\
\text { workload. }\end{array}$ & 0.4 \\
\hline 4 & $\begin{array}{l}\text { Workplace culture - referring to the way in which learning and } \\
\text { residents are valued in the workplace }\end{array}$ & 0.23 & $\begin{array}{l}\text { Facilitator: Culture of the clinical site values residents, listens } \\
\text { to their views and takes appropriate action in response. }\end{array}$ & 0.07 \\
\hline 5 & $\begin{array}{l}\text { Trainer (Senior doctor) skill and support - referring to who does } \\
\text { the training and how they are supported }\end{array}$ & 0.39 & $\begin{array}{l}\text { Barrier: There is an unwillingness to accept that education and } \\
\text { training programmes can be delivered by people other than full } \\
\text { time attendings. }\end{array}$ & 0.2 \\
\hline 6 & $\begin{array}{l}\text { Interaction and feedback in clinical teams- relating to team } \\
\text { dynamics including the provision of feedback to the resident } \\
\text { while working together }\end{array}$ & 0.55 & $\begin{array}{l}\text { Facilitator: Residents learn best when they are challenged to } \\
\text { state what they should do with regard to patient management } \\
\text { and are affirmed and supported in their choices. }\end{array}$ & 0.39 \\
\hline 7 & $\begin{array}{l}\text { Content, assessment and continuity of training - relating to } \\
\text { learning and assessment rooted in clinical practice with effective } \\
\text { communication between senior doctors about performance }\end{array}$ & 0.48 & $\begin{array}{l}\text { Barrier: Poor communication between supervisors for different } \\
\text { clinical placements. }\end{array}$ & 0.46 \\
\hline 8 & $\begin{array}{l}\text { Motivation and morale- relating to morale within the healthcare } \\
\text { system and its impact on the motivation and attitude of learners } \\
\text { and other staff }\end{array}$ & 0.75 & $\begin{array}{l}\text { Barrier: Low morale amongst all staff as they are over worked } \\
\text { and leading to stress and tense staff. }\end{array}$ & 0.41 \\
\hline 9 & $\begin{array}{l}\text { Resident support - referring to reception of the doctor-in-training } \\
\text { into team, collegiality, respect and support to work within scope } \\
\text { of practice and to challenge constructively. }\end{array}$ & 0.36 & $\begin{array}{l}\text { Facilitator: The resident is encouraged to work within his/her } \\
\text { scope of practice to safely develop skills under supervision. }\end{array}$ & 0.34 \\
\hline 10 & $\begin{array}{l}\text { The role of patients in doctors' learning - referring to patient } \\
\text { expectations of care, willingness and provision of feedback }\end{array}$ & 0.44 & $\begin{array}{l}\text { Facilitator: Patients more informed in relation to care provision } \\
\text { and willing to challenge those delivering care. }\end{array}$ & 0.22 \\
\hline
\end{tabular}


Table 3 Cluster ratings for Importance and Ease to Address

\begin{tabular}{|c|c|c|c|c|}
\hline Most to least & Importance (5 = Very Important) & $\begin{array}{l}\text { Mean cluster rating } \\
\text { importance }\end{array}$ & Ease to Address ( $5=$ Very Easy) & $\begin{array}{l}\text { Mean cluster rating } \\
\text { ease to address }\end{array}$ \\
\hline 1 & Cluster 9: Resident support & 3.96 & $\begin{array}{l}\text { Cluster 7: Content, assessment and } \\
\text { continuity of training }\end{array}$ & 3.68 \\
\hline 2 & $\begin{array}{l}\text { Cluster 2: Time to learn with senior } \\
\text { doctors during patient care }\end{array}$ & 3.90 & Cluster 5: Trainer skill and support & 3.56 \\
\hline 3 & $\begin{array}{l}\text { Cluster 6: Interaction and feedback } \\
\text { in clinical teams }\end{array}$ & 3.89 & $\begin{array}{l}\text { Cluster 10: The role of patients in } \\
\text { doctors' training }\end{array}$ & 3.35 \\
\hline 4 & $\begin{array}{l}\text { Cluster 1: Organisation \& conditions } \\
\text { of work }\end{array}$ & 3.81 & Cluster 3: Management \& facilities & 3.20 \\
\hline 5 & Cluster 3: Management \& facilities & 3.73 & Cluster 9: Resident support & 3.19 \\
\hline 6 & Cluster 4: Workplace culture & 3.72 & Cluster 4: Workplace culture & 3.01 \\
\hline 7 & Cluster 8: Motivation and morale & 3.63 & $\begin{array}{l}\text { Cluster 6: Interaction and feedback } \\
\text { in clinical teams }\end{array}$ & 3.01 \\
\hline 8 & $\begin{array}{l}\text { Cluster 10: The role of patients in } \\
\text { doctors' training }\end{array}$ & 3.59 & Cluster 8: Motivation and morale & 2.55 \\
\hline 9 & Cluster 5: Trainer skill and support & 3.51 & $\begin{array}{l}\text { Cluster 1: Organisation and Conditions } \\
\text { of Work }\end{array}$ & 2.51 \\
\hline 10 & $\begin{array}{l}\text { Cluster 7: Content, assessment and } \\
\text { continuity of training }\end{array}$ & 3.42 & $\begin{array}{l}\text { Cluster 2: Time to learn with senior } \\
\text { doctors during patient care }\end{array}$ & 2.37 \\
\hline
\end{tabular}

that all of the domains identified are important to address to enhance resident learning; however, some domains were rated more important than others.

Domains rated most important were those which related to residents' connection to and engagement with more senior doctors and other members of the clinical team (Resident Support, Time to Learn with Senior Doctors during Patient Care and Interaction and Feedback in Clinical Teams). This is in keeping with social learning theory, for example Communities of Practice theory [3], which emphasises the importance for newcomers to a community to learn by working alongside more senior members. Learning, through observation, role modelling, discussion and feedback all takes place in this context. Participants identified shorter working hours, subsequent to the implementation of the European Working Time Directive (EWTD), as disrupting learning through a reduction in time spent with senior doctors and a disintegration of clinical teams. Under the EWTD residents work no more than $48 \mathrm{~h}$ per week in total. Participant statements indicated that less time spent in the clinical environment reduces opportunities to learn through clinical work, to benefit from mentorship and to follow the patient pathway, compounding the challenges of learning in a healthcare system under strain. These perspectives are consistent with some of the literature examining the effects of restricted duty hours [56]; however, published data on the impact of EWTD on training has been mixed [40], perhaps due to the influence of local differences in how the regulations are implemented. In keeping with the GMC national training survey report [57] our findings suggest that poor rota design and scheduling has a negative impact on learning.

Organisation and conditions of work was a strongly coherent and relatively more important domain also identified by participants. Barriers in this domain referred to busyness, service pressure and overcrowding. This emphasises the dual purpose of clinical environments; supporting both patient care and learning, and confirms that service pressures impact opportunities to learn, resulting in cognitive overload, limiting time to reflect and discuss [33], and through constraints on physical space.

Domains relating to the structure and organisation of residency programmes, such as Content, assessment and continuity of training, and Trainer (senior doctor) skill and support were viewed as somewhat less important. When mapped (Fig. 1), it was also apparent that these domains, and that of Management and facilities, were grouped together, distant from Time to learn with senior doctors during patient care, Trainee support and Motivation and morale. The former group of domains can be conceptualised as the imprint of training programmes and management, on the historically, socially and culturally constructed practice of patient care; the formal versus the informal aspects of postgraduate training. Participants identified these formal areas as relatively easy to address, in keeping with fact that improvements and innovations in postgraduate training typically involve changes to content, format and organisation [58-60]. The impact of such changes on day to day learning and supervision has been questioned [59, 61]. Dijkstra et al. [13] found the influence of structural changes on trainees' learning was mediated by 'on the ground' features of the 
clinical learning environment. It has been suggested that local approaches to cultural change may be effective $[59,62]$ in improving clinical learning environments. Our findings suggest that our participants recognised a separation between daily practice and externally determined format and organisation. Programme directors and policymakers need to recognise the limitations of approaches which focus on the latter.

Organisation and conditions of work and Time to learn with senior doctors during patient care were rated as the most difficult areas in which to make improvements. The consensus amongst our participants the combination of heavy clinical workload and duty hour restrictions would be challenging to address may arise from the fact that both are seen as beyond the sphere of influence of academic medicine and healthcare management, but rather the consequences of national economic recession and European legislation. None the less, it is clear that regulators expect those 'on the ground' to deal with these challenges. The General Medical Council (UK) places responsibility for adequate staffing, workload and rota design to support learning on Local Education Providers within the NHS [31] and the Medical Council of Ireland has identified the need for an integrated approach at clinical sites, joining up corporate areas within the health service with responsibility for patient safety and quality of clinical care and those responsible for management of the clinical learning environment [63].

Trainee Support was identified as the most important area to address. This domain refers to reception into the clinical team, collegiality, respect and support to work within scope of practice and to challenge constructively. Participants rated this aspect as moderately easy to address, perhaps because it is within the control of individuals to be welcoming, supportive and respectful of residents. Bullying, and rude, dismissive and aggressive communication are features of healthcare environments internationally [64]. Workload and workplace stress have been shown to trigger such behaviour. Junior members of staff are more likely to be on the receiving end of such communication and it has a negative impact on mental health $[64,65]$.

\section{Implications for practice}

The link between clinical learning environments and the quality and safety of patient care is a strong driver for stakeholders in postgraduate medical education and health service delivery to work together to strengthen both. Our findings point to the relatively greater importance of the informal over formal aspects of workplace learning and a need to prioritise the preservation of residents' opportunities to learn and work alongside senior doctors when service delivery is being planned and structured. There is some evidence that the manner in which restricted duty hours are implemented can mitigate the impact on learning [66]. It has been suggested that affording training programmes flexibility [67] and undertaking precise workload analysis might be helpful [66]. Such an approach would enable learning to be taken into account and optimised in the implementation of compliant rotas and schedules. This approach was recommended in Sir John Temple's 2010 report into the impact of EWTD in the UK [56]; however, there is very little published literature describing innovative ways to comply with duty hours regulations while maximising learning. Further research should focus on exploring the implementation of duty hours' regulations in the full range of training contexts.

A continual focus on residents as learners, in need of and deserving of support from all in the healthcare environment, is essential. Faculty development has been flagged as a key element of high quality postgraduate medical education and provides a means to enhance the value placed on learning and learners in clinical environments [59]. It could also contribute to the 'easy win' identified by participants of ensuring that resident receive more high quality feedback. Culturally embedded negative behaviours towards residents present a significant challenge. Illing et al. [68] make recommendations arising from their review of the literature on bullying which emphasise the importance of senior leadership in initiating culture change. Exploration of other means to generate cultural change with meaningful impact on CLEs and the learning experience of residents is needed [62].

\section{Strengths and limitations}

A strength of this study is that it is a national study which included a wide range of stakeholders in postgraduate medical education and used a rigorous methodological approach to describe their consensus. These are individuals at the frontline of medical training as well as those with more strategic roles; therefore, our findings are rooted in both practice and policy. A limitation of the study is that it was undertaken in the context of the Irish healthcare system and may not be fully transferable to other contexts.

\section{Conclusions}

High quality graduate medical education requires that residents have time to engage and connect with senior doctors during patient care, and that they are valued and supported as both learners and service providers. Academic medicine and health service managers must work together to protect these key elements of clinical learning environments which not only shape learning, but impact patient safety and the quality of patient care. 


\section{Abbreviations}

ACGME: Accreditation Council for Graduate Medical Education; CLE: Clinical Learning Environment; EWTD: European Working Time Directive; GCM: Group Concept Mapping; GME: General Medical Council; NHS: National Health Service; PGME: Postgraduate Medical Education

\section{Acknowledgements}

The authors wish to acknowledge the support and contributions of their patient and clinical site partners in conducting this study.

\section{Funding}

This study was funded by the Health Research Board, Ireland as part of a larger project entitled Exploring Clinical Learning Environments for Postgraduate Medical Education and Training; MERG-899. The funding body did not have a role in the design of the study, collection, analysis, interpretation of data, nor in writing the manuscript.

\section{Availability of data and materials}

The datasets used and/or analysed during the current study are available from the corresponding author on reasonable request.

\section{Authors' contributions}

DB conceived the study. CK, AW, MH, DS, CB, SS and DB designed the study. $\mathrm{CK}, \mathrm{AW}, \mathrm{DB}, \mathrm{AH}, \mathrm{GO} \mathrm{K}^{\prime}, \mathrm{CB}, \mathrm{LP}$ and $\mathrm{MH}$ recruited participants to the study. $\mathrm{CK}$, $A W, D B$ and SS collected the data and conducted the initial analysis. All authors contributed to the interpretation of the findings. DB, CK and AW wrote a draft paper, which has been reviewed and revised critically by all authors. All authors approved the final version to be published and agree to be accountable for all aspects of the work

\section{Ethical approval and consent to participate}

Ethical approval for this study was granted by the Clinical Research Ethics Committee of the Cork University Hospitals. The work was conducted in accordance with the Declaration of Helsinki. All participants were provided with information on the study gave consent.

\section{Consent for publication}

Not applicable.

\section{Competing interests}

The authors declare that they have no competing interests.

\section{Publisher's Note}

Springer Nature remains neutral with regard to jurisdictional claims in published maps and institutional affiliations.

\section{Author details}

'Medical Education Unit, School of Medicine, University College Cork, Cork, Ireland. ${ }^{2}$ Trinity College Dublin, Dublin, Ireland. ${ }^{3}$ Dublin City University Business School, Dublin, Ireland. ${ }^{4}$ Trinity College Dublin Business School, Dublin, Ireland. ${ }^{5}$ School of Medicine, University College Cork, Cork, Ireland. ${ }^{6} \mathrm{~S} c h o o l$ of Nursing and Midwifery, Trinity College Dublin, Dublin, Ireland. ${ }^{7}$ Royal College of Physicians of Ireland, Dublin, Ireland. ${ }^{8}$ Children's University Hospital, Temple St., Dublin, Ireland. ${ }^{9}$ Open University of the Netherlands, Heerlen, Netherlands.

Received: 3 June 2017 Accepted: 7 November 2017 Published online: 22 November 2017

\section{References}

1. Weiss KB, Bagian JP, Nasca TJ. The clinical learning environment: the foundation of graduate medical education. JAMA J Am Med Assoc. 2013; 309:1687-8.

2. Isba R, Boor K. Creating a learning environment. In: Dornan T, Mann KV, Scherpbier A, Spencer J, editors. Medical education. Theory and practice. London: Churchill Livingstone; 2011. p. 99-114.

3. Lave J, Wenger E. Situated learning: legitimate peripheral participation. Cambridge: Cambridge University Press; 1991.

4. Engestrom Y. Expansive learning: toward an activity-theoretical reconceptualization. In Contemporary Theories of Learning Learning Theorists in Their Own Words Volume. 2009;7:53-73.
5. Bandura A. Social cognitive theory: an agentic perspective. Annu Rev Psychol. 2001:52:1-26.

6. Holland D, Lachicotte W, Skinner D, Cain C. Identity and Agency in Cultural Worlds. Book. Cambridge: Harvard University Press; 1998.

7. Billett S. Learning through work : workplace affordances and individual engagement. 2001;13:209-14.

8. Boor K, Van Der Vleuten C, Teunissen P, Scherpbier A, Scheele F. Development and analysis of D-RECT, an instrument measuring residents' learning climate. Med Teach. 2011;33:820-7.

9. Teunissen PW, Scheele F, Scherpbier AJJA, Van Der Vleuten CPM, Boor K Van Luijk SJ, JAAM VD-S. How residents learn: qualitative evidence for the pivotal role of clinical activities. Med Educ. 2007;41:763-70.

10. Daelmans HE, Hoogenboom RJ, Donker AJ, Scherpbier AJ, Stehouwer CD, van der Vleuten CP. Effectiveness of clinical rotations as a learning environment for achieving competences. Med Teach. 2004;26(September):305-12.

11. Wimmers PF, Schmidt HG, Splinter TA. Influence of clerkship experiences on clinical competence. Med Educ. 2006:40:450-8.

12. Tokuda Y, Goto E, Otaki J, Jacobs J, Omata F, Obara H, Shapiro M, Soejima K, Ishida Y, Ohde S, Takahashi O, Fukui T. Undergraduate educational environment, perceived preparedness for postgraduate clinical training, and pass rate on the National Medical Licensure Examination in Japan. BMC Med Educ. 2010;10:35.

13. Dijkstra IS, Pols J, Remmelts P, Rietzschel EF, Cohen-Schotanus J, Brand PLP. How educational innovations and attention to competencies in postgraduate medical education relate to preparedness for practice: the key role of the learning environment. Perspect Med Educ. 2015;4:300-7.

14. Wiener-Ogilvie S, Bennison J, Smith V. General practice training environment and its impact on preparedness. Educ Prim Care. 2014;25:8-17.

15. Cross V, Hicks C, Parle J, Field S. Perceptions of the learning environment in higher specialist training of doctors: implications for recruitment and retention. Med Educ. 2006:40:121-8.

16. Gracey CF, Haidet P, Branch WT, Weissmann P, Kern DE, Mitchell G, Frankel $\mathrm{R}$, Inui T. Precepting humanism: strategies for fostering the human dimensions of care in ambulatory settings. Acad Med. 2005:80:21-8.

17. Moyer CA, Arnold L, Quaintance J, Braddock C, Spickard A, Wilson D, Rominski S, Stern DT. What factors create a humanistic doctor? A nationwide survey of fourth-year medical students. Acad Med. 2010;85:1800-7.

18. Asch DA, Nicholson S, Srinivas S, Herrin J, Epstein AJ. Evaluating obstetrical residency programs using patient outcomes. JAMA -J Am Med Assoc. 2009; 302:1277-83.

19. Chen C, Petterson S, Phillips R, Bazemore A, Mullan F. Spending patterns in region of residency training and subsequent expenditures for care provided by practicing physicians for Medicare beneficiaries. JAMA -J Am Med Assoc. 2014;312:2385-93.

20. Medical Council. Your training counts. Ireland: Dublin; 2014

21. GMC. National Training Survey 2013. In: London; 2013.

22. WFME: Postgraduate Medical Education. WFME Global Standards for Quality Improvement. Copenhagen; 2003

23. ACGME: CLER pathways to excellence. Expectations for an Optimal Clinical Learning Environment to Achieve Safe and High Quality Patient Care. Chicago; 2014.

24. Daniels T, Williams I, Robinson S, Spence K. Tackling disinvestment in health care services the views of resource allocators in the English NHS. J Health Organ Manag. 2013;27:762-80.

25. Budhdeo S, Watkins J, Atun R, Williams C, Zeltner T, Maruthappu M. Changes in government spending on healthcare and population mortality in the European union, 1995-2010: a cross-sectional ecological study. J R Soc Med. 2015;108:490-8.

26. Karanikolos M, Mladovsky P, Cylus J, Thomson S, Basu S, Stuckler D, Mackenbach JP, Mckee M. Health in Europe 7 financial crisis, austerity, and health in Europe. Lancet. 2013;6736:1-9.

27. Dixon-Woods M, Baker R, Charles K, Dawson J, Jerzembek G, Martin G, McCarthy I, McKee L, Minion J, Ozieranski P, Willars J, Wilkie P, West M. Culture and behaviour in the English National Health Service: overview of lessons from a large multimethod study. BMJ Qual Saf. 2014;23:106-15.

28. Di Somma S, Paladino L, Vaughan L, Lalle I, Magrini L, Magnanti M. Overcrowding in emergency department : an international issue. IntEmerg Med. 2015:10:171-5.

29. Moskop JC, Sklar DP, Geiderman JM, Schears RM, Bookman KJ. Emergency department crowding, part 1-concept, causes, and moral consequences. Ann Emerg Med. 2009;53:605-11. 
30. Cameron PA. Hospital overcrowding: a threat to patient safety? Med J Aust. 2006;184:203-4

31. General Medical Council. Promoting excellence: standards for medical education and training. In: London; 2016.

32. General Medical Council. National Training Survey 2016 key findings. In: Manchester; 2016.

33. Haney EM, Nicolaidis C, Hunter A, Chan BK, Cooney TG, Bowen JL. Relationship between resident workload and self-perceived learning on inpatient medicine wards: a longitudinal study. BMC Med Educ. 2006;6:35.

34. Rabatin J, Williams E, Baier Manwell L, Schwartz MD, Brown RL, Linzer M. Predictors and outcomes of burnout in primary care physicians. J Prim Care Community Health. 2016;7:41-3.

35. Visser MRM, Smets EMA, Oort FJ, de Haes H. Stress, satisfaction and burnout among Dutch medical specialists. Can Med Assoc J. 2003;168:271-5.

36. Jennings ML, Slavin SJ. Resident Wellness Matters. Acad Med. 2015;90:1246-50.

37. Virtanen M, Batty GD, Pentti J, Vahtera J, Oksanen T, Tuisku K, Salo P, Terho K, Ahola K, Elovainio M, Kivimäki M. Patient overcrowding in hospital wards as a predictor of diagnosis-specific mental disorders among staff: a 2-year prospective cohort study. J Clin Psychiatry. 2010;71:1308-12.

38. Reader TW, Gillespie A. Patient neglect in healthcare institutions: a systematic review and conceptual model. BMC Health Serv Res. 2013;13:156.

39. Axelrod L, Shah J, Jena AB. The European working time directive. An uncontrolled experiment in medical care and education. JAMA -J Am Med Assoc. 2013;309:447

40. Moonesinghe SR, Lowery J, Shahi N, Millen A, Beard JD. Impact of reduction in working hours for doctors in training on postgraduate medical education and patients' outcomes: systematic review. BMJ. 2011;342(January):d1580.

41. Wong BM, Imrie K. Why resident duty hours regulations must address attending physicians' workload. Acad Med. 2013;88:1209-11.

42. Bolster $L$, Rourke $L$. The effect of restricting residents' duty hours on patient safety, resident well-being, and resident education: an updated systematic review. J Grad Med Educ. 2015;7:349-63.

43. Weiss KB, Bagian JP, Wagner R. CLER pathways to excellence: expectations for an optimal clinical learning environment (executive summary). J Grad Med Educ. 2014;6:610-1.

44. Wong B, Holmboe E. Transforming the academic faculty perspective in graduate medical education to better align educational and clinical outcomes. Acad Med. 2016:91:473.

45. Goddard AF, Aldridge C, Leong KS, Freemantle N, Rimmer A. Lessons to be learned from the UK junior doctors' strike. JAMA -J Am Med Assoc. 2016; 316:1445.

46. Jacques H. Irish doctors strike over "dangerous" working hours. BMJ Careers. 2013;

47. Bennett D, Dornan T, Bergin C, Horgan M: Exodus? The training paths and plans of postgraduate medical trainees, under the Royal College of Physicians of Ireland. Ir J Med Sci 2014, Epub Mar 9.

48. Campbell D. Almost half of junior doctors reject NHS career after foundation training. The Guardian. 2015.

49. Packer MJ, Goicoechea J. Sociocultural and constructivist theories of learning: ontology, not just epistemology. Educ Psychol. 2000;35:227-41.

50. Hasson F, Keeney S, McKenna H. Research guidelines for the Delphi survey technique. J Adv Nurs. 2000;32:1008-15.

51. Stoyanov S, Boshuizen $\mathrm{H}$, Groene $\mathrm{O}$, van der Klink M, Kicken W, Drachsler $\mathrm{H}$, Barach P. Mapping and assessing clinical handover training interventions. BMJ Qual Saf. 2012:21(Suppl 1):i50-7.

52. Concept Systems Incorporated: Concept System Global Max.

53. Wopereis I, Kirschner P, Paas F, Stoyanov S, Hendricks M. Failure and success factors of educational ICT projects: a group concept mapping approach. $\mathrm{Br}$ J Educ Technol. 2005;36:681-4.

54. Hynes H, Stoyanov S, Drachsler H, Maher B, Orrego C, Stieger L, Druener S, Sopka S, Schröder H, Henn P. Designing learning outcomes for handoff teaching of medical students using group concept mapping. Acad Med. 2015;90:1.

55. Stoyanov S, Spoelstra H, Bennett D, Sweeney C, Van Huffel S, Shorten G, O'Flynn S, Cantillon-Murphy P, OTuathaigh C, Burgoyne L. Use of a group concept mapping approach to define learning outcomes for an interdisciplinary module in medicine. Perspect Med Educ. 2013;

56. Temple J: Time for Training. A Review of the Impact of the European Working Time Directive on the Quality of Training. London; 2010(May).

57. GMC: 2017 National Training Surveys Summary Report: initial results on doctors ' training and progression. London; 2017.
58. lobst WF, Sherbino J, Cate OTEN, Richardson DL, Dath D, Swing SR, Harris P, Mungroo R, Holmboe ES, Frank JR. The FOR, Cbme I: competency-based medical education in postgraduate medical education. Med Teach. 2010:651-6.

59. Mortensen L, Malling B, Ringsted C, Rubak S. What is the impact of a national postgraduate medical specialist education reform on the daily clinical training 3.5 years after implementation? A questionnaire survey. BMC Med Educ. 2010;10:46

60. Patel M. Changes to postgraduate medical education in the 21 st century. Clin Med (Northfield II). 2016;16:311-4.

61. Hopmans CJ, Hoed PT Den, Wallenburg I, Laan L Van Der, Harst E Van Der, Elst M Van Der, Mannaerts GHH, Dawson I, Lanschot JJB Van, ljzermans JNM: Surgeons' attitude toward a competency- based training and assessment program : results of a multicenter survey. J Surg Educ 2013, 70:647-654.

62. Skipper M, Musaeus $P$, Nøhr SB. The paediatric change laboratory: optimising postgraduate learning in the outpatient clinic. BMC Med Educ. 2016:1-12.

63. Medical Council of Ireland. Doctors ' education, training and lifelong learning in 21st century Ireland. Ireland: Dublin; 2015.

64. Bradley V, Liddle S, Shaw R, Savage E, Rabbitts R, Trim C, Lasoye TA, Whitelaw BC. Sticks and stones: investigating rude, dismissive and aggressive communication between doctors. Clin Med (Northfield II). 2015; 15:541-5.

65. Paice $\mathrm{E}$, Aitken M, Houghton A, Firth-Cozens J. Bullying among doctors in training:cross sectional questionnaire survey. BMJ Br Med J. 2004;329:658-9.

66. Schimmack S, Hinz U, Wagner A, Schmidt T, Strothmann H, Büchler MW, Schmitz-Winnenthal $\mathrm{H}$. Maximizing time from the constraining European working time directive (EWTD): the Heidelberg new working time model. Health Econ Rev. 2014:4:14.

67. Bilimoria KY, Chung JW, Hedges LV, Dahlke AR, Love R, Cohen ME, Hoyt DB, Yang AD, Tarpley JL, Mellinger JD, Mahvi DM, Kelz RR, Ko CY, Odell DD, Stulberg JJ, Lewis FR. National Cluster-Randomized Trial of duty-hour flexibility in surgical training. N Engl J Med. 2016;374:713-27.

68. Illing J, Carter M, Thompson NJ, Crampton PES, Morrow GM, Howse JH, Cooke A, Burford BC: Evidence Synthesis on the Occurrence, Causes, Management of Bullying and Harassing Behaviours to Inform Decision Making in the NHS. NIHR Service Delivery and Organisation Programme; 2013(February).

\section{Submit your next manuscript to BioMed Central and we will help you at every step:}

- We accept pre-submission inquiries

- Our selector tool helps you to find the most relevant journal

- We provide round the clock customer support

- Convenient online submission

- Thorough peer review

- Inclusion in PubMed and all major indexing services

- Maximum visibility for your research

Submit your manuscript at www.biomedcentral.com/submit 